( 1995 Elsevier Science B.V. All rights reserved.

\title{
In situ FTIR microscopic investigation of the acid sites in cloverite
}

\author{
G. Müller, G. Eder-Mirth and J.A. Lercher
}

Christian Doppler Laboratory for Heterogeneous Catalysis and University of Twente, Department of Chemical Technology, P.O. Box 217, 7500 AE Enschede, The Netherlands.

The acidity of cloverite was studied by sorption of probe molecules with varying basicity. Cloverite possesses two types of structural hydroxyl groups (Ga-OH and $\mathrm{P}-\mathrm{OH}$ groups) which exhibit high and moderate Brönsted acid strength towards apolar hydrocarbon molecules. Sorption of polar base molecules on the Ga-OH groups, however, leads to a breaking of the Ga$\mathrm{O}$ bond close to the $\mathrm{Ga}-\mathrm{OH}$ adsorption site resulting in a concerted Lewis and Brönsted type interaction. For small molecules (like ammonia), multiple sorption at these sites causes a local rearrangement of the lattice leading to a collapse of the microporous structure upon thermal desorption of the probe molecules. Small alcohols are chemisorbed quite differently on the $\mathrm{Ga}-\mathrm{OH}$ groups of cloverite compared to other acidic molecular sieves leading to the formation of dimethylether and formaldehyde upon desorption.

\section{INTRODUCTION}

Cloverite, a microporous gallophosphate has attracted great attention as it possesses unusually large micropores [1-3]. Because of its potential as sorbent and catalyst for the reactions of larger organic molecules, the structure was thoroughly characterized by various techniques [17]. A major drawback for its application, however, is the instability of the microporous structure in ambient atmosphere once the template is removed. This is also the main reason why rather limited information is available on the sorption and catalytic properties of the molecular sieve [1$4,6]$.

The aim of this contribution is to characterize the nature and strength of the acid sites of cloverite by sorption and reactive desorption of probe molecules. The molecules studied were the strong bases ammonia, pyridine and trimethylamine as well as alcohols with varying chain length (methanol, ethanol and propanol)

\section{EXPERIMENTAL}

\subsection{Material}

We used single crystals with hexagonal/square shape with a diameter between 80 and 140 $\mu \mathrm{m}$. as well as polycrystalline material (particle size of $\sim 1 \mu \mathrm{m}$ ). Both samples were provided by Dr. H. Kessler, Laboratoire de Matériaux Minéraux, Ecole Nationale Supérieure de Chimie, Mulhouse. Cloverite possesses two non intersecting 3-dimensional pore systems. The large pore system consists 20 membered rings with a free diameter of approximately $1.3 \mathrm{~nm}$, the other pore 
system is formed by 8 membered rings showing a free diameter of only $\sim 0.4 \mathrm{~nm}$. At the intersections of the large pores, supercages are formed which exhibit a diagonal diameter of 2.9 $\mathrm{nm}$ [1-3]. The lattice of cloverite is neutral consisting of alternating $\mathrm{PO}_{4}$ - and $\mathrm{GaO}_{4}$ - tetrahedra. The terminal hydroxyl groups which are an integral part of the lattice are located in the large pore system (see fig. 1).

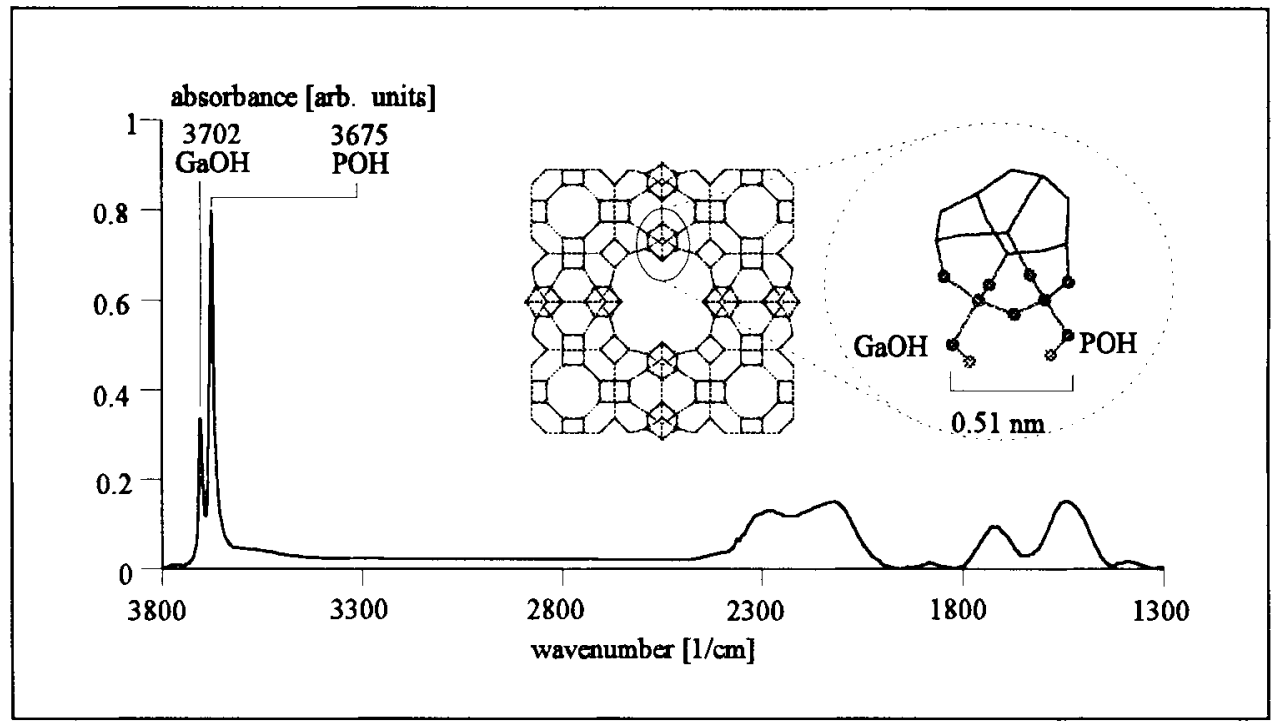

Figure 1: Spectrum of the activated cloverite and graphic representation of a part of the unit cell (enlarged, the part where the structural hydroxyl groups are situated). In the representation of the part of the unit cell, only the T-atoms are connected

\subsection{Sorption studies}

Activation, sorption and desorption were followed in situ by time resolved FTIR microscopy. The measurements on the single crystals were carried out in a vacuum cell equipped with i.r. transparent windows attached to the stage of a BRUKER i.r. microscope. The spectrometer used was a BRUKER IFS $88\left(4 \mathrm{~cm}^{-1}\right.$ spectral resolution).

The polycrystalline material was pressed into self supporting wafers and measured in another high vacuum cell which was placed in the BRUKER IFS 88 spectrometer. This cell was connected to a BALZERS QMG 410 mass spectrometer which was used to monitor the gas phase composition during temperature programmed desorption.

The template was removed by heating the sample with $10 \mathrm{~K} / \mathrm{min}$ up to $800 \mathrm{~K}$ in air, holding this temperature for two hours and subsequently evacuating the system to $10^{-6} \mathrm{mbar}$ and cooling it to $300 \mathrm{~K}$ to perform the sorption experiments. The structure of the activated molecular sieve was stable in vacuum or inert gas atmosphere. The sorbates were introduced into the reaction cell via a gas inlet system at a temperature of $300 \mathrm{~K}$. The desired partial pressure was held constant until sorption/desorption equilibrium was achieved and was then increased in steps from $10^{-3}$ to 
1 mbar. Subsequently, the system was again evacuated to $10^{-6}$ mbar for 90 minutes, followed by temperature programmed desorption (TPD, heating rate $10 \mathrm{~K} / \mathrm{min}$, final temperature between 800 and $900 \mathrm{~K}$ ).

\section{RESULTS AND DISCUSSION}

\subsection{Acid sites in cloverite}

The i.r. spectrum of the activated cloverite (fig. 1) showed two absorption bands at 3702 and $3675 \mathrm{~cm}^{-1}$, which are assigned to $\mathrm{Ga}-\mathrm{OH}$ and $\mathrm{P}-\mathrm{OH}$ groups, respectively [8]. Upon sorption of benzene, the i.r. bands of these $\mathrm{OH}$ groups were broadened and shifted to lower wavenumbers ( $\Delta v=250 \mathrm{~cm}^{-1}$ for the Ga-OH and $220 \mathrm{~cm}^{-1}$ for the $\mathrm{P}-\mathrm{OH}$ group, compared to the $260 \mathrm{~cm}^{-1}$ shift observed for SiOHAl groups of HZSM-5). Because the magnitude of the red shift of the $\mathrm{OH}$ bands after adsorption of a donor molecule is directly proportional to the acid strength of the $\mathrm{OH}$ group [9], this indicates high and moderate acid strength of the $\mathrm{OH}$ groups of cloverite.

The absorption bands in the spectral region below $2500 \mathrm{~cm}^{-1}$ are assigned to overtones and combinations of the lattice vibrations of the gallium phosphate [10].

\subsection{Sorption of strong bases}

The nature and accessibility of the acid sites in cloverite was probed by sorption of three bases molecules, ammonia, pyridine and trimethylamine (TMA). These molecules have different proton affinities and kinetic diameters, with ammonia having the lowest proton affinity and the smallest kinetic diameter. The i.r. spectra of ammonia and pyridine sorbed on cloverite show characteristic absorption bands for Lewis $\left(1616 \mathrm{~cm}^{-1}\right.$ for ammonia and $1613 \mathrm{~cm}^{-1}$ for pyridine) as well as Brønsted (1450 $\mathrm{cm}^{-1}$ for ammonia and $1543 \mathrm{~cm}^{-1}$ for pyridine) bonded species [11]. With increasing coverage, the absorption bands of both species increased parallel in intensity, while the intensity of both types of $\mathrm{OH}$ groups decreased. It should be emphasized that preferential sorption on one of the sorption sites (Ga-OH or P-OH groups) was not found. After equilibration at 0.1 mbar at $300 \mathrm{~K}$, all hydroxyl groups were found to interact with base molecules.

Bonding to cloverite was concluded to be strong, as desorption did not occur upon evacuation at $300 \mathrm{~K}$. During temperature programmed desorption (TPD), pyridine and TMA desorbed first from the $\mathrm{P}-\mathrm{OH}$ group (maxima of the rate of desorption around $800 \mathrm{~K}$ ). The molecules interacting with the $\mathrm{Ga}-\mathrm{OH}$ groups could only be partially desorbed up to $900 \mathrm{~K}$ in vacuum, but were completely removed upon treatment in flowing air at $800 \mathrm{~K}$. This unusual high thermal stability and the simultaneous disappearance of the free hydroxyl groups and the appearance of the bands characteristic for Lewis and Brönsted bonded species led us to conclude that the Bronsted acidity of cloverite cannot account alone for the strong sorption of the base molecules

For ammonia, the removal of the molecules by the above described thermal treatments $(900$ $\mathrm{K}$ in vacuum, $800 \mathrm{~K}$ in air) did not lead to the reappearance of the $\mathrm{OH}$ stretching vibration bands characteristic for the cloverite structure. Then, only a small band at $3675 \mathrm{~cm}^{-1}$ characteristic for $\mathrm{P}-\mathrm{OH}$ groups was observed. This spectrum was similar to that recorded after sorption of water at ambient temperature (followed by TPD) which led to a collapse of the microporous structure [2]. In agreement with Patarin et al.[3] we therefore conclude that the same occurs in the presence of ammonia at elevated temperatures. An amorphization of cloverite after a stepwise thermal desorption of ammonia was confirmed by XRD measurements [3] 
As pyridine and TMA have stronger gas phase basicities than ammonia and their sorption did not lead to an irreversible change/damage of the lattice, we conclude the size of the molecule to be a decisive factor for the destabilization of the cloverite structure.

These results clearly indicate that a concerted interaction of Brönsted and Lewis acid sites occurs upon sorption of the base molecules on cloverite. This concept of a concerted interaction of Lewis and Brönsted acid sites implies that upon sorption, one of the $\mathrm{Ga}-\mathrm{O}$ bonds next to the $\mathrm{Ga}-\mathrm{OH}$ group is partially opened and that the primary interaction takes place between the then accessible $\mathrm{Ga}$ cation and the base molecule. This might induce a rehybridization of the $\mathrm{Ga}$ cation from tetrahedral symmetry first to a 5-fold coordination (like it is present in the "as synthesized" form) and then to complete octahedral (corresponding to 6fold) coordination (fig.2). The 6-fold coordination is possible for the smaller ammonia molecules, as they can enter also the small pore system (free inner diameter $\sim 0.4 \mathrm{~nm}$ ) and coordinate to the $\mathrm{Ga}$ cations through the double 4 rings connecting the large with the small pore system (as shown in figs. 1 and 2). For the larger pyridine and TMA molecules a cleavage of the $\mathrm{Ga}-\mathrm{O}$ bond still occurs and leads to a Lewis type coordination between the $\mathrm{Ga}$ cation and the base molecule. However, the additional interaction of a second molecule via the small pore system cannot be achieved leading only to a five fold coordination of the Ga upon sorption of these molecules.

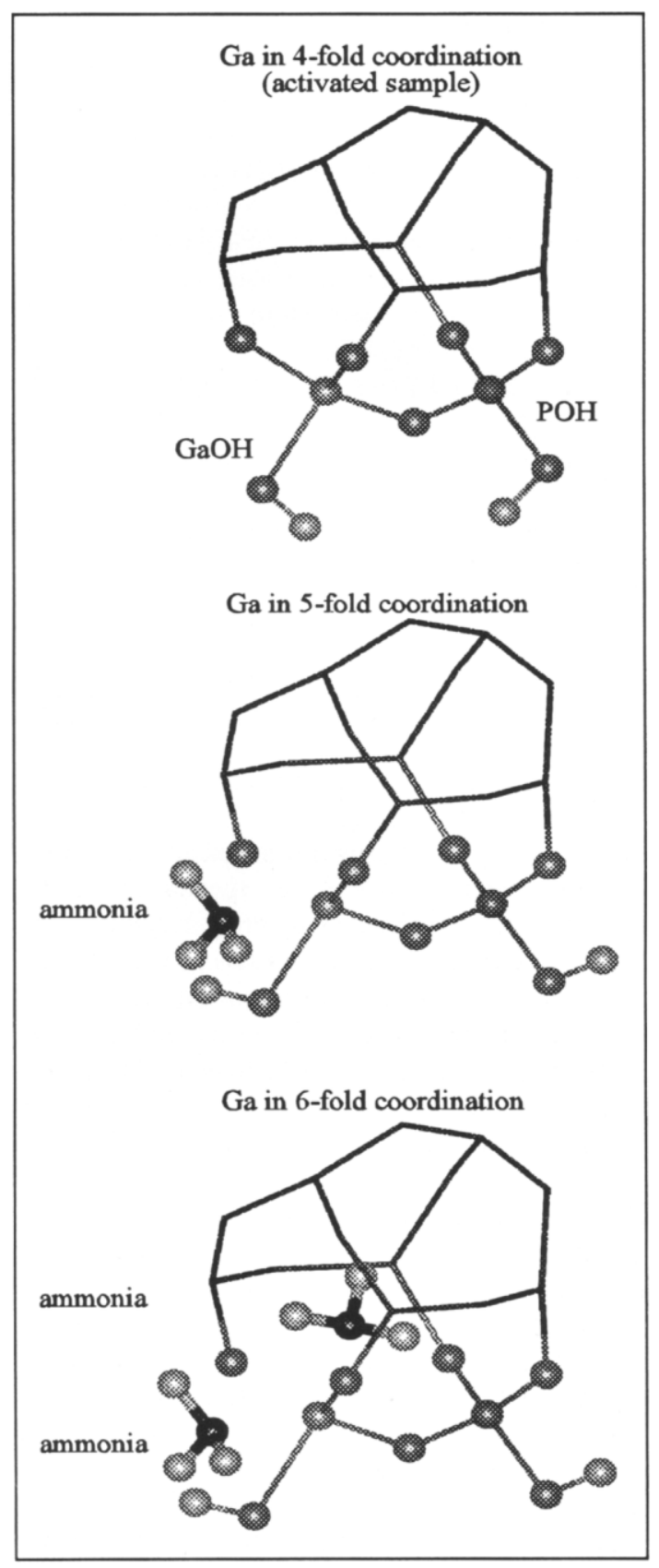

Figure 2: Change in coordination of gallium upon sorption of ammonia 


\subsection{Sorption of alcohols}

While the sorption of the strongly basic molecules occurred in parallel on both types of hydroxyl groups, preferential interaction with the Ga-OH groups was noticed with the alcohols (methanol, ethanol and propanol). This effect was quite pronounced with methanol and decreased in importance with increasing molecular weight of the alcohol. Note that all $\mathrm{Ga}-\mathrm{OH}$ groups interacted with an alcohol molecule at rather low partial pressures $\left(10^{-3} \mathrm{mbar}\right)$, while the partial pressures required to cover all $\mathrm{P}-\mathrm{OH}$ groups were decreased with increasing chain length (see table 1).

Tablel

Uptake characteristics of alcohols on Brönsted acid sites

\begin{tabular}{lcc}
\hline Alcohol & $\begin{array}{c}\Theta_{(\mathrm{P}-\mathrm{OH})} \text { at } \Theta_{(\mathrm{Ga}-\mathrm{OH})}=1 \\
{[1]}\end{array}$ & $\begin{array}{c}\mathrm{P}_{\mathrm{eq}} \text { to reach } \Theta_{(\mathrm{P}-\mathrm{OH})}=1 \\
{[\mathrm{mbar}]}\end{array}$ \\
\hline Methanol & 0 & 1 \\
Ethanol & 0.25 & 0.1 \\
Propanol & 0.6 & 0.01 \\
\hline
\end{tabular}

$\Theta$ coverage $P_{\text {eq. }} \ldots$. equilibrium pressure

After equilibration with $10^{-3} \mathrm{mbar}$, all $\mathrm{Ga}-\mathrm{OH}$ groups interacted with methanol molecules. The i.r. spectra of the sorbed species recorded during the uptake of methanol suggest the existence of two different sorption structures on the $\mathrm{Ga}-\mathrm{OH}$ groups [8]. At low coverages, structure A which is characterized by bands of the $\mathrm{CH}$ stretching vibrations at 2828 and $2940 \mathrm{~cm}$ ${ }^{1}$, was dominant. After longer exposure (corresponds also to higher coverages) a shoulder rose at $2838 \mathrm{~cm}^{-1}$ and a new peak appeared at $2950 \mathrm{~cm}^{-1}$. These bands were attributed to a second sorption structure of methanol (structure B). Under these conditions, the P-OH groups were not affected by methanol adsorption.

At partial pressures higher than $10^{-3} \mathrm{mbar}$, methanol interacted also with the $\mathrm{P}-\mathrm{OH}$ groups causing bands of $\mathrm{CH}$ stretching vibrations at 3000,2962 and $2855 \mathrm{~cm}^{-1}$ (structure C). These absorption maxima are close to those observed for methanol hydrogen bonded to weakly acidic silanol groups $\left(3001,2958\right.$ and $\left.2856 \mathrm{~cm}^{-1}\right)$ [12]. Thus, we suggest a similar type of interaction for methanol sorbed on the P-OH groups of cloverite.

It should be emphasized that the bands of the $\mathrm{CH}$ stretching vibrations of methanol interacting with the $\mathrm{Ga}-\mathrm{OH}$ groups occurred at quite low wavenumbers, comparable only with the values observed for methanol sorbed on $\mathrm{Rb}$ - of Cs-cations in alkali exchanged X-zeolites [13]. This led us to conclude that the interaction of methanol with the $\mathrm{Ga}-\mathrm{OH}$ groups cannot be ascribed to hydrogen bonding or protonation like in other acidic zeolites [14], but an additional interaction of the hydrogen bonded molecules with Lewis type sites has to be assumed. Based on these results and the evidences collected for the sorption of strong bases, we conclude that also upon sorption of methanol, a $\mathrm{Ga}-\mathrm{O}$ bond neighboring the $\mathrm{Ga}-\mathrm{OH}$ group is broken creating a strong Lewis acid site next to the hydroxyl group. 
The i.r. spectra of ethanol and propanol sorbed on cloverite showed only absorption features characteristic for an alcohol molecule interacting via hydrogen bonds with acidic hydroxyl groups [14]. Thus, it is difficult to judge whether ethanol and propanol are polar enough to cause the same type of lattice opening as it was observed with methanol.

Upon evacuating the system, almost complete desorption of methanol and ethanol from the $\mathrm{P}-\mathrm{OH}$ groups was observed. However, about $30 \%$ of the $\mathrm{P}-\mathrm{OH}$ groups still showed interaction with propanol under these conditions. Such a behavior can only be explained, if we assume that propanol interacts with the $\mathrm{P}-\mathrm{OH}$ and the $\mathrm{Ga}-\mathrm{OH}$ groups simultaneously. This seems possible

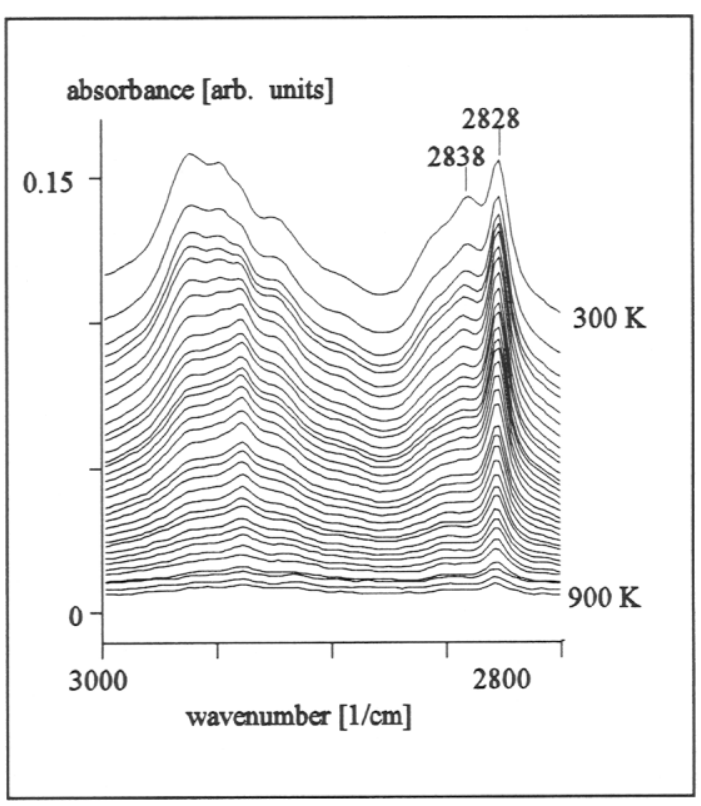

Figure 3: I.r. spectra recorded during TPD of methanol from cloverite because of the steric vicinity of the two structural $\mathrm{OH}$ groups (average distance between them is $0,51 \mathrm{~nm}$ and the length of the propanol molecule is $0,53 \mathrm{~nm}$. See also fig.1.). It should be noted that evacuation at ambient temperature did not affect the interaction of the alcohol molecules with the $\mathrm{Ga}-\mathrm{OH}$ groups.

In addition to unreacted methanol, the formation of two different products, dimethylether and formaldehyde was observed during temperature programmed desorption (TPD) of methanol from cloverite. The i.r.spectra recorded during TPD of methanol from polycrystalline cloverite are shown in fig.3. Dimethylether formation occurred at lower temperatures (maximum rate of desorption around $500 \mathrm{~K}$ ) and is directly correlated to the disappearance of structure B from the surface. The other sorption species (mainly species A) desorbed as formaldehyde at higher temperatures (maximum rate of desorption around $670 \mathrm{~K}$ ).

Upon increasing the temperature, ethanol and propanol desorbed partly unreacted from the $\mathrm{Ga}-\mathrm{OH}$ groups. At temperatures above $500 \mathrm{~K}$, dehydration of the alcohols took place leading to the formation of water, ethene and propene. Other reaction products were not detected by mass spectrometry.

\section{CONCLUSIONS}

The structural hydroxyl groups of cloverite exhibit high and moderate Brønsted acid strength towards apolar hydrocarbon molecules. With polar molecules, these hydroxyl groups show unique interactions leading to a local rearrangement of the lattice including a breaking of the $\mathrm{Ga}-\mathrm{O}$ bond close to the $\mathrm{Ga}-\mathrm{OH}$ sorption site. Consequently, a concerted Lewis and Brönsted acid type interaction is concluded to exist between the basic molecules and the $\mathrm{Ga}-\mathrm{OH} / \mathrm{Ga}$ cation sorption 
sites. This type of interaction is paralleled by a change in the coordination of the Ga cation to first 5 -fold (upon sorption of 1 probe molecule) and then, after sorption of a second molecule to complete 6-fold (octahedral) coordination. This 6-fold coordination can only be achieved, if the probe molecule is small enough (like water or ammonia) to enter the small pore system and to coordinate to the Ga cation via the double 4 rings. Desorption of the molecules from the octahedral coordination, leads to a collapse of the microporous structure of cloverite and results in the formation of an amorphous $\mathrm{GaPO}_{4}$.

Methanol sorbs preferentially on the $\mathrm{Ga}-\mathrm{OH}$ groups leading to two different sorption structures. One coordinatively bound species to Ga cations which desorbs reactively as formaldehyde at elevated temperatures. The other structure is attributed to methanol hydrogen bonded to the $\mathrm{Ga}-\mathrm{OH}$ groups and yields dimethylether upon desorption.

\section{ACKNOWLEDGEMENT}

The work was partially founded by the Christian Doppler Laboratory for Heterogeneous Catalysis. The graphic displays shown in figures 1 and 2 were printed out from the INSIGHT II molecular modeling system (BIOSYM Technologies Inc.). We thank Dr.Henri Kessler for providing the cloverite samples.

\section{REFERENCES}

1. M.Esterman, L.B.McCusker, C.Baerlocher, A.Merrouche and H.Kessler, Nature 352 (1991) 320 .

2. A.Merrouche, J.Patarin, H.Kessler, M.Soulard, L.Delmotte, J.L.Guth and J.F.Joly, Zeolites 12 (1992) 226.

3. J.Patarin, C.Schott, A.Merrouche, H.Kessler, M.Soulard, L.Delmotte, J.L.Guth and J.F.Joly, Proc. 9th IZC; van Ballmoos, R. et al.; Butterworth-Heinemann, 1993, 263.

4. R.L.Bedard, C.L.Bowes, N.Combes, A.J.Holmes, T.Jiang, S.J.Kirkby, P.M.Macdonald, A.M.Malek, G.A.Ozin, S.Petrov, N.Plavac, R.A.Ramik, M.R.Steele, and D.J.Young, Am. Chem. Soc. 115 (1993) 2300.

5. B.Zibrowius, M.W.Anderson, W.Schmidt, F.F.Schüth, A.E.Aliev and K.D.Harris, Zeolites 1993, 13, 607

6. T.L.Barr, J.Klinowski, H.He, K.Alberti, G.Müller and J.A.Lercher, Nature 365 (1993) 429.

7. S.Bradley, R.F.Howe and J.V.Hanna, Solid State Nuclear Magn. Res. 2 (1993) 37

8. G.Müller, G.Eder-Mirth, H.Kessler and J.A.Lercher, J.Phys.Chem. submitted 1995.

9. M.L.Hair and W.Hertl, J. Phys. Chem. 74 (1970) 91.

10. V.V.Krymova, L.E.Kitaev, A.A.Kubasov, Z.V.Gryaznova, L.S.Eshchenko and V.V. Pechkovskii, Vestn. Mosk. Univ., Ser. 2. Khim. 20(5) (1979) 476.

11. L.H.Little, "Infrared Spectra of Adsorbed Species", Academic Press, London, 1966. E.P.Parry, J. Catal. 2 (1963) 371

12. B.A.Morrow, J.Chem. Soc.Farad.I 70 (1974) 1527

13. G.Eder-Mirth, H.Wanzenböck and J.A.Lercher, ZEOCAT 95, accepted for publication.

14. M.T.Aronson, R.J.Gorte and W.E.Farneth, J.Catal. 105 (1987) 455.

G.Mirth, A.Kogelbauer and J.A.Lercher, Proc. 9th IZC; van Ballmoos, R. et al;; Butterworth-Heinemann, 1993, 251. 